\title{
Patient's satisfaction with nursing care on the post-surgery of radical prostatectomy
}

\author{
Satisfação do paciente com os cuidados de enfermagem no pós-operatório de \\ prostatectomia radical
}

Carla Fernanda Marcelino ${ }^{1}$, Katya Araújo Machado Saito ${ }^{1}$, Ana Lúcia Silva Mirancos da Cunha² ${ }^{2}$ Audry Elizabeth dos Santos ${ }^{1}$

Objetivo: avaliar a satisfação do paciente e suas experiências vivenciadas com o cuidado de enfermagem no pós-operatório de prostatectomia radical aberta. Métodos: estudo transversal, realizado com 60 pacientes. Foram utilizados ficha de caracterização pessoal e clínica dos sujeitos e a versão brasileira do instrumento Newcastle Satisfaction with Nursing Scales. Realizada análise descritiva dos dados e de correlação das características dos pacientes com escores de satisfação e experiência do paciente. Resultados: a satisfação dos pacientes e a vivência de experiências positivas com os cuidados de enfermagem no período pós-operatório foram relacionados principalmente ao papel educacional da equipe de enfermagem, habilidade de comunicação e respeito a privacidade. Pacientes que com hospitalização prévia em outra instituição apresentaram nível de satisfação maior comparado aos que não tiveram hospitalização anterior. Conclusão: pacientes submetidos à prostatectomia radical aberta vivenciaram experiências positivas e demostraram alto nível de satisfação com o cuidado de enfermagem.

Descritores: Satisfação do Paciente; Cuidados de Enfermagem; Prostatectomia.

Objective: to evaluate the satisfaction of patient and his experiences with nursing care in the post-surgery of open radical prostatectomy. Methods: cross sectional study carried out with 60 patients. It was used a form with personal and clinical characterization of subjects and the Brazilian version of instrument Newcastle Satisfaction with Nursing Scales. It was used descriptive analysis of data and of correlation of the patient's characteristics with satisfaction scores and patient experience. Results: the patients' satisfaction and experience of positives experiences with nursing care in the post-surgery period was related mainly to educational role of the nursing team, communication skill and respect to privacy. Patients with previous hospitalization in other institution showed higher satisfaction level compared with those that not have previous hospitalization. Conclusion: patients submitted to open radical prostatectomy had positives experiences and demonstrated higher level of satisfaction with nursing care.

Descriptors: Patient Satisfaction; Nursing Care; Prostatectomy.

\footnotetext{
${ }^{1}$ Hospital Sírio-Libanês. São Paulo, SP, Brazil.

${ }^{2}$ Hospital Beneficência Portuguesa de São Paulo. São Paulo, SP, Brazil.

Author corresponding: Carla Fernanda Marcelino

Rua Herculano de Freitas, 131, Bela Vista. CEP: 01308-020. São Paulo, SP, Brazil. E-mail: carlafmar@gmail.com
} 


\section{Introduction}

Patient satisfaction is defined as the degree of convergence between the expectations and the perception about the care received, in other words, it is an evaluation that results from a comparative process between the care experienced and the care expected to receive ${ }^{(1-2)}$. It is considered an important indicator of quality of health institutions, and the nursing team needs more and more to obtain knowledge of the factors that impact in the patient's perception about the care offered ${ }^{(3-4)}$.

For the patients that need some surgical intervention, post-surgery period comprehends a specific moment of orientations to the patient and relatives about the care that will be developed in the care unit and at home, in order to prepare them for hospital discharge and for prevention of post-surgery complications $^{(5)}$.

When referring to radical prostatectomy, the nursing team's performance becomes even more relevant, since there are a lot of expectations and doubts by the patient regarding their recovery ${ }^{(5-6)}$. Prostate cancer is one of the most diagnosed malignant neoplasms in men worldwide. Its incidence increases with age and reaches about $50.0 \%$ of men with 80 years $^{(7-8)}$.

Nowadays, three types of surgical approach can be described: open approach retropubic radical prostatectomy, laparoscopic and robotic; being the open radical prostatectomy considered standard reference for located prostate cancer treatment, with surgical approach technic that evolved with time, with decrease of the surgical incision and the risks of bleeding in intra-surgical; with greater possibility of preservation of urinary continence and erectile function, in addition to have less cost than other types of techniques, and be reproducible and accessible for public and private hospitals $^{(8)}$.

Nursing assistance to the prostatectomy patient involves a set of specific cares during post-surgery, that aim the effective prepare of patient for hospital discharge. Some of these actions imply involvement of the patient itself and the family in care, such as care with the indwelling catheters, with urine drainage bag and the surgical incision bandage ${ }^{(5-6)}$.

Researches show that patients more satisfied and with positive experiences of care participate in a much more efficient way on the self-care and has better adherence to instructions and information received in hospitalization period, besides generating a more positive institution evaluation ${ }^{(1,3-4)}$, and nowadays there is a gap in the Brazilian literature with the meaning to evaluate urologic patient satisfaction.

In this context, it becomes relevant to identify if these patients are satisfied with the nursing care and which are the most important aspects that influence satisfaction and experience that urologic patients experience with nursing assistance in hospital environment. The objective of the study was to evaluate the patient satisfaction and its experiences with nursing care in the post-surgery of open radical prostatectomy.

\section{Methods}

Descriptive, exploratory and cross-sectional study, performed on period of February to August 2015 in a large private hospital in the city of São Paulo, which structure comprehends 469 hospital beds and that develops aside from assistance to patients with medium and large complexities, teaching and research activities.

The population was composed by hospitalized patients in urological unit of the hospital of the study and submitted to radical prostatectomy. It was used a non-probabilistic convenience sampling and it was obtained a total of 60 participants. As inclusion criteria it was considered the patients submitted to open radical prostatectomy and were excluded from the study patients on post-surgery that have not been hospitalized in the urological unit of the hospital (as in an intensive care unit), or in any conditions that hinders to sign the consent form and to answer the questions of the data collection instruments.

For data collect two instruments were applied: 
personal characterization form (age and marital status) and the subjects' clinical (hospitalization period, comorbidities, previous hospitalizations, level of prostatic antigen); and the Brazilian version of Newcastle Satisfaction with Nursing Scales (B-NSNS). The B-NSNS is an instrument translated and adapted to Brazilian culture, that besides evaluating the satisfaction level the patient with nurse care, measures experiences with relation to the assistance provided during the hospitalization period ${ }^{(4,9)}$.

The instrument has two evaluation scales: Patient's experience to nursing care with eight items on the Brazilian version. The measure is Likert type scale that varies from one to seven, in which alternatives vary from "Disagree completely" to "Agree completely". The other scale is the Patient satisfaction with nursing care, with eighteen items, with a measure Likert-type scale that varies from one to five and with response alternatives that vary from "not at all satisfied" to "completely satisfied"(4). The reliability of the Brazilian version of the instrument, expressed by the Cronbach alpha coefficient, resulted in satisfactory values: 0.85 for the Patient's experience to nursing care scale and 0.97 for the Patient's experience to nursing care $^{(4,9)}$.

The participants of the study were approached in the urologic unit of the hospital, by one of the researchers, in a moment that would not compromise nursing assistance and hospital routine. The approaches of patients happened from the third day of post-surgery, for two reasons: the author of the original instrument recommends that interviews occur with patients with twenty-four hours or more of hospitalization ${ }^{(4)}$; and for the fact that the patient submitted to open radical prostatectomy has medium time of hospitalization of four days in the institution of the study. The patients that agreed to participate in the study signed the free and informed consent form in two copies and one of them was given to the participant.

The data obtained from the instruments' application were typed in a spreadsheet program Ex- cel ${ }^{\circledR}$ and analyzed through Stata ${ }^{\circledR}$ program (version 11.2). After consistency, check of data it was used the descriptive analysis with usage of absolute frequencies and percentages for the categorical variables. For quantitative variables, it was used measures of central tendency (mean or median), of dispersion (standard deviation) and of position, using percentile of $25.0 \%$ $\left(Q_{1}\right)$ and percentile of $75.0 \%\left(Q_{3}\right)$.

For the score calculation of both Brazilian versions of Newcastle Satisfaction with Nursing Scales, the proposed orientations for the original version of the instrument were followed. One item had its score recoded in an inverted way for calculation of total score $^{(4,10)}$. In the end, the two scales' score can vary from zero to one-hundred, in which the greater score obtained, more positive experiences were experienced by the patient and greater the level of satisfaction with nursing care ${ }^{(4,10)}$.

It was evaluated the correlation between the scores obtained in the two scales and between the score obtained in each scale and the patients' age with use of Spearman correlation coefficient. The scores obtained in each scale were compared regarding characteristic of patients (marital study, educational degree, previous hospitalization in the same hospital, previous hospitalization in other hospitals and presence of comorbidity) through the Mann-Whitney test. Statistical significance level of $\mathrm{p}<0.05$ was admitted.

The research Project was previously submitted to evaluation by Research Ethics Committee from the institution of the study and approved according to report $\mathrm{n}$-943.772. The study complied the national and international ethics standards that regulate the development of researches with human beings.

\section{Results}

The patients' age varied from 42 to 79 years ( mean $=62.1$ years; standard deviation $=7.7$ years $)$. Thirty-eight (63.3\%) patients had 60 years or more of age, $54(90.0 \%)$ were married and $44(73.3 \%)$ concluded higher education. Five 9 (8.3\%) patients have 
already been hospitalized before on the hospital (four of them for surgical treatment and one for clinical treatment) and 41 (68.3\%) had history of previous hospitalization in other hospitals.

Regarding the presence of comorbidity, 42 (70.0\%) patients presented at least one. The comorbidities more frequently identified on the patients were: systemic arterial hypertension 27 (45.0\%), dyslipidemia 21 (35.0\%) and diabetes mellitus 11 (18.3\%).

The patients reported high frequency of total agreement with the items of Patient's experience to nursing care scale with nursing care. The first item The nursing team gave information just when I needed it, presented total agreement of $90.0 \%$ of the participants, followed by item four: The nursing team checked regularly to make sure I was okay, with $86.7 \%$ of agreement. Items two and five of the scale: The nursing team, as busy as they were, always had time for me and The nursing team explained what was happening with me, respectively, showed total agreement of $80.0 \%$ of the participants. The total score obtained in this scale varied from 69.6 to $100\left(\right.$ median $\left.=94.6 ; p_{25 \%}=92.0 ; p_{75 \%}=94.6\right)$. Three $(5.0 \%)$ patients obtained score below 80 .

In six of the 18 items that composes the Patient satisfaction with nursing care scale, $45(75.0 \%)$ of patients answered being totally satisfied and in any item was observed an answer "not at all satisfied" (Table 1).The total score obtained in this scale varied from 60 to 100 (median $=97.8 ; Q_{1}=86.1 ; Q_{3}$ $=100.0)$.

Table 1 - Answers to the items of Patient satisfaction with nursing care scale of the patients submitted to open radical prostatectomy

\begin{tabular}{|c|c|c|c|c|}
\hline \multirow[t]{2}{*}{ Patient satisfaction with nursing care } & $\begin{array}{c}\text { Little } \\
\text { satisfied }\end{array}$ & Satisfied & $\begin{array}{c}\text { Very } \\
\text { satisfied }\end{array}$ & $\begin{array}{c}\text { Completely } \\
\text { satisfied }\end{array}$ \\
\hline & n (\%) & n (\%) & n (\%) & n (\%) \\
\hline How much the nursing team was capable in their job & - & $9(15.0)$ & $11(18.3)$ & $40(66.7)$ \\
\hline The presence of someone from the nursing team when always needed & - & $6(10.0)$ & $10(16.7)$ & $44(73.3)$ \\
\hline How much the nursing team knew about the care I needed & - & $7(11.7)$ & $11(18.3)$ & $42(70.0)$ \\
\hline How quickly nurse team came when you called & $1(1.7)$ & $11(18.3)$ & $10(16.7)$ & $38(63.3)$ \\
\hline The way the nursing team did to make you feel comfortable & - & $5(8.3)$ & $13(21.7)$ & $42(70.0)$ \\
\hline $\begin{array}{l}\text { The amount of information that the nursing team gave to you about your condition and } \\
\text { treatment }\end{array}$ & - & $8(13.3)$ & $11(18.3)$ & $41(68.3)$ \\
\hline The frequency the nursing team checked if you were good & - & 7 (11.7) & $10(16.7)$ & $43(71.7)$ \\
\hline The nursing team's disposition in helping & - & 7 (11.7) & $8(13.3)$ & $45(75.0)$ \\
\hline The way the nursing team explained the things to you & - & $6(10.0)$ & $10(16.7)$ & $44(73.3)$ \\
\hline The nursing team's help to tranquilize its relatives and friends & $1(1.7)$ & $10(16.7)$ & $10(16.7)$ & $39(65.0)$ \\
\hline The way the nursing team did their job & - & $10(16.7)$ & $9(15.0)$ & $41(68.3)$ \\
\hline The information the nursing team gave you about your condition and treatment & - & $10(16.7)$ & $8(13.3)$ & $42(70.0)$ \\
\hline The attention that the nursing team gave you as a person & - & $7(11.7)$ & $8(13.3)$ & $45(75.0)$ \\
\hline The way how the nursing team heard your concerns and anxieties & - & 10 (16.7) & $10(16.7)$ & $40(66.7)$ \\
\hline The amount of freedom that was given in the unit & - & $6(10.0)$ & $9(15.0)$ & $45(75.0)$ \\
\hline The nursing team's disposition to attend your needs & $1(1.7)$ & $8(13.3)$ & $6(10.0)$ & $45(75.0)$ \\
\hline The amount of privacy that the nursing team gave to you & - & $6(10.0)$ & $9(15.0)$ & $45(75.0)$ \\
\hline The awareness of the nursing team about your necessities & $1(1.7)$ & $1(1.7)$ & $7(11.7)$ & $45(75.0)$ \\
\hline
\end{tabular}


It was not observed significant correlations between the patient's age and total score obtained in the Patient's experience to nursing care $(\rho=-0.15$; $\mathrm{p}=0.246)$ and between age and total score obtained in Patient satisfaction with nursing care $(\rho=-0.13$; $\mathrm{p}=0.313$ ).

The scores of both scales of the Brazilian version of Newcastle Satisfaction with Nursing Scales do not represent normal distribution (Shapiro-Wilk test: $\mathrm{p}<0,001)$. On the analysis of correlation of obtained scores in both scales, through the Spearman coefficient, it was obtained a positive moderated significant correlation $(\rho=0.47 ; p<0.001)$.

It was not observed significant differences in the total scores obtained on the Patient satisfaction with nursing care scale according to marital status, educational level, previous hospitalizations and presence of comorbidity (Table 2).

Table 2 - Score in the patient's experience to nursing care scale, according to the patients' characteristics submitted to open radical prostatectomy

\begin{tabular}{|c|c|c|c|c|c|}
\hline \multirow[t]{2}{*}{ Variables } & \multicolumn{5}{|c|}{$\begin{array}{c}\text { Patient's experience to } \\
\text { nursing care }\end{array}$} \\
\hline & $\mathbf{n}$ & $\mathbf{Q}_{1}{ }^{1}$ & Median & $\mathrm{Q}_{3}{ }^{2}$ & $\mathbf{p}^{*}$ \\
\hline Marital status & & & & & 0.147 \\
\hline Married & 54 & 92.9 & 94.6 & 94.6 & \\
\hline Separated/widow & 6 & 85.7 & 92.9 & 94.6 & \\
\hline Educational level & & & & & 0.944 \\
\hline Up until completed high school & 11 & 92.9 & 94.6 & 94.6 & \\
\hline Higher education or higher schooling & 49 & 91.1 & 94.6 & 94.6 & \\
\hline \multicolumn{4}{|c|}{ Previous hospitalization in the hospital of the study } & & 0.465 \\
\hline No & 55 & 92.9 & 94,6 & 94.6 & \\
\hline Yes & 5 & 87.5 & 98.2 & 100 & \\
\hline Previous hospitalization in other hospitals & & & & & 0.973 \\
\hline No & 19 & 87.5 & 94.6 & 98.2 & \\
\hline Yes & 41 & 92.9 & 94.6 & 94.6 & \\
\hline Comorbidities & & & & & 0.728 \\
\hline No & 18 & 92.9 & 94.6 & 94.6 & \\
\hline Yes & 42 & 91.1 & 94.6 & 94.6 & \\
\hline
\end{tabular}

Patients with previous hospitalization history in the hospital where the study was carried out, presented lower score in Patient's satisfaction with nursing care scale than patients that never had been hospitalized in the same institution, although this difference did not represent statistical significance.

In contrast, the patients with previous hospitalization in other hospitals showed higher score than those that did not have hospitalization experience $(p=0.03 . p=0.05$ ) (Table 3). It was not observed other statistically significance differences in the scores of this scale according to other patients' characteristics.

Table 3 - Score in the Patient's satisfaction with nursing care, according to the patients' characteristics submitted to open radical prostatectomy

\begin{tabular}{|c|c|c|c|c|c|}
\hline \multirow[t]{2}{*}{ Variables } & \multicolumn{5}{|c|}{$\begin{array}{c}\text { Patient's satisfaction with } \\
\text { nursing care }\end{array}$} \\
\hline & $\mathbf{n}$ & $\mathrm{Q}_{1}{ }^{1}$ & Median & $\mathbf{Q}_{3}{ }^{2}$ & $\mathbf{p}^{*}$ \\
\hline Marital status & & & & & 0.575 \\
\hline Married & 54 & 86.7 & 97.8 & 100.0 & \\
\hline Separated/widow & 6 & 82.2 & 93.9 & 100.0 & \\
\hline Educational level & & & & & 0.540 \\
\hline Up until completed high school & 11 & 78.9 & 94.4 & 100.0 & \\
\hline Higher education or higher schooling & 49 & 87.8 & 97.8 & 100.0 & \\
\hline
\end{tabular}

Previous hospitalization in the hospital of the study

$\begin{array}{lllll}\text { No } & 55 & 87.8 & 97.8 & 100.0 \\ \text { Yes } & 5 & 74.4 & 75.6 & 91.1\end{array}$

Previous hospitalization in other hospitals $0.030^{* *}$ No

$19 \quad 74.4 \quad 94.4 \quad 100.0$

Yes $\begin{array}{llll}41 & 94.4 & 98.9 & 100.0\end{array}$

Comorbidities

No

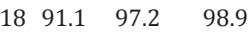

Yes

$42 \quad 85.5 \quad 98.9 \quad 100.0$

${ }^{1} \mathrm{Q}_{1}$ : percentile $25 \% ;{ }^{2} \mathrm{Q}_{3}$ : percentile $75 \%$; ${ }^{*}$ Mann-Whitney Test; ${ }^{* *} \mathrm{p}<0.05$

\section{Discussion}

It is highlighted as the study's limitations the transversal design and the not approach of patients submitted to other techniques other than radical prostatectomy. However, it was evident the factors that impact the patient's satisfaction and experience on care received during hospitalization period, making possible for the nursing professionals to identify such as- 
pects in their assistance practice and to develop strategies and competencies for the patient-centered care.

The age variable is relevant in this study, because it corroborates with what the literature represents in relation to age range (50-69 years) in which happens the prostate cancer diagnostic among men in Brazilian population. Also, most of the patients reported to have some comorbidity and the most prevalent preexisting diseases in the participants were systemic arterial hypertension, dyslipidemia and diabetes mellitus. This is an important data, because according to a national epidemiologic study about patients with diagnosed cancer, the presence of comorbidity is a depending factor on the access to health services and diagnostic procedures, in other words, patients that already have medical follow-up due some clinical condition, can have the possibility of early prostate cancer diagnosis ${ }^{(10)}$.

Regarding the answers obtained in the Patient's experience with nursing cares scale, all participants agreed on the item "The nursing team gave information just when I needed it". This question reinforces the important nursing team's role: patient and family education.

For the surgical patient, inform and guide him to surgical prepare procedures, evaluate the patient's evolution conditions on post-surgery, clarify doubts and provide individualized assistance can contribute to anxiety decrease of the patient and for the strengthen of bonds between nursing team and patient $t^{(6)}$. Studies that investigate the relation between patient expectation and nursing care, demonstrated that most of the patients that evaluated nursing care as bad, reported communication failure and lack of adequate information about health, disease and treatment conditions as the main cause of dissatisfaction ${ }^{(4,11-12)}$.

The item "The nursing team verified regularly to make sure if I was okay" was the second of greater concordance in this scale; in which reinforces the importance of one of the nursing team's fundamental activity that is the patient's vigilance. The patient's mo- nitoring during the post-surgery period can provide a feeling well cared of. In this way, it is verified that the vigilance permits to identify factors that may lead to alterations in the health state of the patient and complications on post-surgery ${ }^{(12-13)}$.

In general, the patients' experiences in post-surgery of radical prostatectomy were positive and the satisfaction degree was high. In comparison with other international studies and with the Brazilian studies that originates the Brazilian version of Newcastle Satisfaction with Nursing Scales ${ }^{(9)}$, the scores obtained in both the scales of the instrument were similar ${ }^{(1,11,14)}$.

Patients that had previous hospitalization in other hospitals presented greater levels of satisfaction with nursing care, than the ones that had not been hospitalized previously. The fact that most of the patients had been hospitalized previously in another health institution, favored the comparative process between the services in institutions they had contact.

The items that most patients were completely satisfied were those related to the nursing team's disposition and attention, to the educational role, communication, to the individual treatment of the patient, acknowledgement and attendance of their necessities and respect to their privacy and freedom during hospitalization ${ }^{(9)}$. International studies conducted with patients from various cultures about their expectations regarding nursing care during hospitalization period, pointed that the aspects more cited and that interfered negatively on the perception of nursing care quality are low abilities of effective communication, less respect to privacy and freedom, discontinuity care, indifferent attitude and lack of empathy ${ }^{(12,15-16)}$.

According to the correlation analysis between the two scales of Brazilian version of Newcastle Satisfaction with Nursing Scales, the positive correlation of moderate magnitude proves the results found in this and in other studies that utilize the same instrument: the more positive experiences the patient has with nursing care during hospitalization period, the more will be their satisfaction ${ }^{(9,11,14)}$. 
Nowadays, the theme of patient experience has been the focus of studies and leaders in health, because of its strong relation to general experience of patient and better results for patient and institution. Among the factors that most impact on patient experience are: period with the doctor, health professional interpersonal abilities, provision of information and clear explanation, cultural aspects of care and pain management ${ }^{(17)}$.

Therefore, investing on individualized and holistic care, improve the effective communication between team, patient and relatives; disposition of doubt clearance in relation to treatment and disease; on attending the expectations and having attention and empathy to the necessities of each patient, aside from ensuring adequate prepare for hospital discharge, is a factor of positive impact and differential on experience and satisfaction of the patient with the care.

\section{Conclusion}

The patients submitted to open radical prostatectomy had positive experiences with nursing care during the hospitalization period and demonstrated high levels of satisfaction with the care received, especially for the characteristics according to respect to privacy and freedom, communication and educational roles from the nursing team.

\section{Collaborations}

Marcelino CF contributed to the conception, project, analysis, and data interpretation, article writing, critical relevant review of the intellectual content and final approval of the version to be published. Saito KAM, Cunha ALSM and Santos AE contributed with critical relevant revision of intellectual content and approval of the final version to be published.

\section{References}

1. Dorigan GH, Guirardello EB. Translation and crosscultural adaptation of the Newcastle Satisfaction with Nursing Scales into the Brazilian culture. Rev Esc Enferm USP. 2013; 47(3):562-8. doi: dx.doi. org/10.1590/S0080-623420130000300006

2. Tronchin DMR, Melleiro MM, Takahashi RT. A qualidade e a avaliação dos serviços de saúde e de enfermagem. Rio de Janeiro: Guanabara Koogan; 2016.

3. Acosta AM, Marques GQ Levandovski PF, Peralta JP, Lima MADS. Satisfação dos usuários com cuidados de enfermagem em serviço de emergência: uma revisão integrativa. Rev Min Enferm. 2016; 20:e938. doi: dx.doi.org/10.5935/14152762.20160008

4. Girmay A, Marye T, Haftu M, Gher D, Brhanu $\mathrm{T}$, Gerensea H. Patient expectation strongly association with patients perceptions to nursing care: hospital based cross sectional study. BMC Res Notes. 2018; 11:1-6. doi: dx.doi.org/10.1186/ s13104-018-3447-x

5. Cardozo AS, Santana RF, Rocha ICM, Cassiano KM, Mello TD, Melo UG. Acompanhamento por telefone como intervenção de enfermagem na recuperação cirúrgica de idosos prostatectomizados. Rev Enferm UFPE on line [Internet]. 2017 [citado 2018 out 18];11(8):3005-12. Disponível em: https:// periodicos.ufpe.br/revistas/revistaenfermagem/ article/viewFile/110203/22101

6. Lima WG, Nunes SFL, Alvarez AM, Valcarenghi RV, Bezerra MLR. Main nursing diagnoses in hospitalized elderly people who underwent urological surgery. Rev Rene. 2015; 16(1):7280. doi: http://dx.doi.org/10.15253/21756783.2015000100010

7. Dall'Oglio M, Crippa A, Srougi M. Câncer de próstata. São Paulo: Santos; 2013.

8. Ministério da Saúde (BR). Instituto Nacional de Câncer José de Alencar Gomes da Silva (INCA). Câncer de Próstata [Internet]. 2018 [citado 2018 out 18]. Disponível em:http://www2.inca.gov.br/ wps/wcm/connect/tiposdecancer/site/home/ prostata 
9. Dorigan GH, Oliveira HC, Guirardello EB. Predictors of patients' experiences and satisfation with nursing care in medical medical-surgical wards. Texto Contexto Enferm. 2015; 24(4):10038. doi: http://dx.doi.org/10.1590/01040707201500002520014

10. Oliveira MM, Malta DC, Guauche H, Moura L, Silva GA. Estimativa de pessoas com câncer no Brasil: dados da Pesquisa Nacional de Saúde, 2013. Rev Bras Epidemiol. 2015; 18(2):146-7. doi: dx.doi. org/10.1590/1980-5497201500060013

11. Kol E, Arikan F, Ilaslan E, Akinci MA. A quality indicator for the evaluation of nursing care: determination of patient satisfaction and related factors at university hospital in the Mediterranean Region in Turkey. Collegian. 2018; 25(1):51-6. doi: https://doi.org/10.1016/j.colegn.2017.03.006

12. Negash KA, Negussie WD, Demissie AF. Patients' satisfaction and associated factors with nursing care services in selected hospitals, Northwest Ethiopia. Am J Nurs Sci. 2014; 3(3):34-42. doi: dx.doi.org/10.11648/j.ajns.20140303.12
13. Aiken LH, Sloane DM, BallJ, etal. Patientsatisfaction with hospital care and nurses in England: an observational study. BMJ Open. 2018; 8(1):1-8. doi: dx.doi.org/10.1136/ bmjopen-2017-019189

14. Alasad J, Tabar NA, Aburuz ME. Patient satisfaction with nursing care. J Nurs Adm. 2015; 45(11):563-68. doi: http://dx.doi.org/10.1097/ NNA.0000000000000264

15. Agbele TO, Nwambo JC, Ukamaka CN. Patients' perception of quality nursing care in a Federal Medical Centre. Int J Health Sci. 2018; 4(1):15. doi: http://dx.doi.org/10.14445/24547484/ IJNHS-V4I1P101

16. Oppel EM, Young GJ. Nursing staffing patterns and patient experience of care: an empirical analysis of the US hospitals. Health Serv Res. 2018; 53(3):1799-18. doi: dx.doi.org/10.1111/14756773.12756

17. Sonis JD, Asronson EL, Lee RY, Philpotts LL, White BA. Emergency department patient experience: a systematic review of the literature. J Patient Exp. 2018; 5(2):101-6. doi: dx.doi. org/10.1177/2374373517731359 